\title{
Neuropsychological disorders after coronary bypass surgery
}

\author{
Tania Walzer, Manfred Herrmann, Claus-W Wallesch
}

\begin{abstract}
Objectives-A prospective assessment of neuropsychological impairment in the early postoperative stage after coronary bypass surgery.

Methods-Seventy patients undergoing elective coronary bypass surgery (CABG) were investigated preoperatively, two to three and five to nine days postoperatively with a comprehensive neuropsychological assessment including orientation, word fluency, naming, arithmetic, memory, and visuoconstructive tasks.

Results-Patients exhibited significant early postoperative impairment affecting all tasks but naming. Except for the orientation measurement, most patients recovered by the fifth to ninth postoperative day. Only six patients had delirium according to DSM III-R criteria on the second or third postoperative day. Cluster analysis of neuropsychological data obtained on the second to third postoperative day identified 10 patients who were cognitively compromised. As a group, these patients had required a greater number of defibrillations and exhibited lower cardiac indices postoperatively. Preoperatively, patients at risk for postoperative dysfunction were characterised by lower verbal memory, word fluency, and clock orientation scores. Conclusions-Simple preoperative neuropsychological assessment may be helpful and clinically applicable in identifying patients at risk for postoperative cognitive dysfunction and may contribute to improve postoperative management aiming at the prevention of delirium or other transient neuropsychological disorders.
\end{abstract}

(F Neurol Neurosurg Psychiatry 1997;62:644-648)

Keywords: neuropsychology; delirium; follow up; coronary bypass surgery

Various studies have reported that psychiatric-for example, delirium, depression-and neuropsychological alterations-for example, disorientation, and memory and attention disorders-occur in proportions of patients undergoing cardiovascular surgery with extra- corporeal circulation, but the results are discrepant (up to $100 \%$ with a peak incidence of $\left.30 \%^{1}\right)$. The incongruities are probably related to variations in definition, time and type of assessment, patient selection, and changes in indication and surgical procedures over the years. Also, study designs differed widely: prospective investigations yielded much higher incidence rates than retrospective ones. ${ }^{2}$ The most often used assessment procedures were interviews, the Wechsler adult intelligence scale, and the mini mental state examination, ${ }^{3}$ which do not detect subtle neuropsychological deficits. With few exceptions, ${ }^{4-7}$ the studies investigated the presence of neuropsychological impairment seven days or more after surgery. Clinically, the peak incidence of postoperative delirium is in the first few days. ${ }^{89}$

Many predisposing and precipitating factors for neuropsychological and psychopathological disorders after heart surgery are described in the vast literature on the topic, such as age, pre-existing cardiac, neurological, and psychiatric disease, drugs and withdrawal, personality traits, perfusion time, intraoperative hypothermia, hypotension, duration of artificial respiration and treatment in an intensive care unit, and sensory and sleep deprivation. ${ }^{10}$

The present study aimed at a prospective assessment of the incidence of neuropsychological impairments (including delirium as defined by DSM III-R ${ }^{11}$ ) in the early postoperative stage after CABG surgery using statistical methods to identify affected patients and subjects at risk. Because of the reported peak incidence of neuropsychological disorders in the first few days after the operation and the lack of studies covering the early postacute stage after heart surgery, we sought to investigate patients as shortly as possible after surgery with follow up a few days later.

Patients and methods

Ninety eight consecutive patients of the Freiburg University Department of Cardiac and Vascular Surgery admitted for elective CABG fulfilled the following selection criteria:

- Native German speaker

- Routine surgery for acquired cardiac pathology

- No ICU treatment required preoperatively

- NYHA-status < IV 
- No simultaneous other surgery-for example, carotid endarterectomy

- No history of neurological or psychiatric morbidity or substance misuse

- Informed and written consent to participate.

Twenty eight patients were excluded for the following reasons:

- Preoperative signs of focal brain lesions ( $=8)$

- Perioperative or postoperative stroke $(n=$ 4)

- Perioperative mortality $(n=2)$

- Postoperative haemorrhagic complication that precluded investigation $(\mathbf{n}=3)$

- Reoperation within first postoperative week $(n=4)$

- Assisted ventilation $>72$ hours $(n=2)$

- Sedation during the second postoperative day $(n=3)$

- Discharge before second postoperative investigation could be performed $(n=2)$.

Complete data sets could be obtained from

70 patients who fulfilled the inclusion criteria. A standard cardiopulmonary bypass technique with membrane oxygenator, non-pulsatile flow, and mean arterial pressure control was used. Patients were hypothermic at $29^{\circ} \mathrm{C}$. Anaesthesia consisted of premedication with lormetazepame or flunitrazepame, induction with narcuronium, fentanyl, and a barbiturate or benzodiazepine and maintenance with fentanyl, flunitrazepame, narcuronium, nitrous oxide, and oxygen. $\mathrm{PCO}_{2}$ was kept constant at $40 \mathrm{~mm} \mathrm{Hg}$. Patients were extubated 8-18 hours postoperatively and transferred from intensive care between the first and third postoperative day. Table 1 gives the demographic and clinical data of the CABG patient group.

The patients were assessed on the last or next to the last preoperative day, on the second or third postoperative day; (median two days) and on the fifth to ninth postoperative

Table 1 Clinical and demographic variables

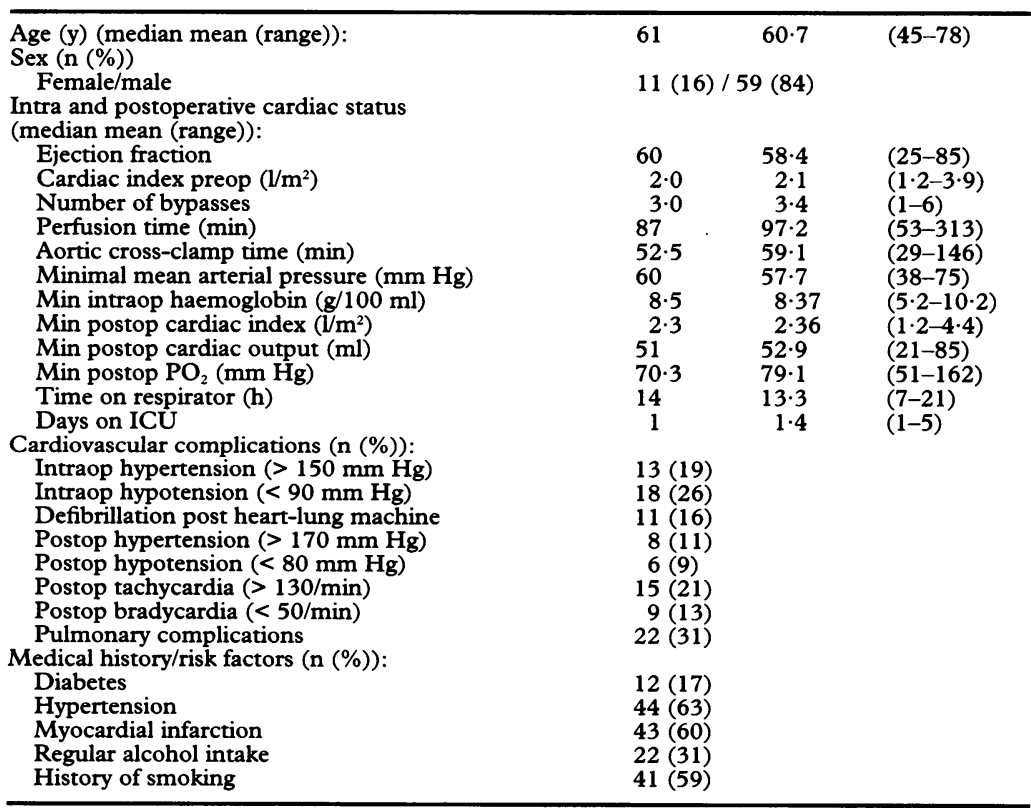

day (median five days). The following procedures and instruments were used:

(1) A clinical neurological examination to rule out preoperative and perioperative focal brain lesion.

(2) The mini mental state examination $\left(\mathrm{MMSE}^{3}\right.$ ) with separate scoring for orientation and cognitive status (three parallel versions given in pseudorandom order),

(3) Word fluency: the patient had to produce as many words as possible starting with the letter $G$ (parallel versions: $T$ and $M$, given in pseudorandom order). During two minutes the number of words of different lexical roots was scored. This task is supposed to assess lexical integrity, psychomotor speed, and left frontal lobe dysfunction.

(4) Naming: the patient was asked to give the names of 10 line drawings of common objects drawn on A5 white cardboard. Besides lexical access, this task also assesses visual analysis and gnosis.

(5) Arithmetic: 12 tasks involving simple operations of addition, subtraction, multiplication, and division were presented.

(6) Verbal memory: the patients were asked to reproduce as many as possible from a list of 10 words that was read aloud. The procedure was repeated four times with the same list of words.

(7) Clock reading: the patient was required to state the time from eight pictures of an analogue clock (without numbers but with marks for every five minutes). Deviations of \pm 1 minute were accepted. This task was included as a simple assessment of visuoconstructive abilities without motor requirements.

Three psychometrically evaluated parallel versions were used in pseudorandom order. The described neuropsychological instruments allow a bedside investigation under intensive care conditions without motor activity. The whole examination took 20 to 30 minutes.

STATISTICAL ANALYSIS

Analysis of intragroup differences was performed with non-parametric procedures (Mann-Whitney $U$ tests, Wilcoxon tests, and $\chi^{2}$ test) as a ceiling effect of data distribution was expected. Levels of significance are two tailed with $\alpha$ adjustment (Bonferroni) for multiple comparisons. The analysis of neuropsychologically affected patients and risk factors was performed with a multivariate statistical procedure (hierarchical cluster analysis).

\section{Results}

Table 2 gives medians and ranges of the neuropsychological assessments. With the exception of the naming task significant variation was found in all cognitive domains that were assessed. Group effects showed an impairment of neuropsychological function at the second to third postoperative day, most of which was recovered by the fifth to ninth day. At the second postoperative examination orientation was the only impaired function.

The figure shows box plots of the MMSE results separately for orientation and cognition 
Table 2 Neuropsychological performance before and on days 2-3 and 5-9 after bypass surgery

\begin{tabular}{|c|c|c|c|}
\hline \multirow[b]{2}{*}{ Neuropsychological performance } & \multicolumn{3}{|l|}{ Bypass surgery } \\
\hline & $\begin{array}{l}\text { Before } \\
\text { Median (range) }\end{array}$ & $\begin{array}{l}\text { After } \\
\text { Days 2-3 } \\
\text { Median (range) }\end{array}$ & $\begin{array}{l}\text { After } \\
\text { Days 5-9 } \\
\text { Median (range) }\end{array}$ \\
\hline $\begin{array}{l}\text { MMSE orientation }(\max 10) \\
\text { MMSE cognition }(\max 20) \\
\text { Word fluency } \\
\text { Naming (max } 10) \\
\text { Arithmetic }(\max 12) \\
\text { Verbal memory }(\max 40) \\
\text { Clock reading }(\max 8)\end{array}$ & $\begin{array}{l}10(9-10)^{\star \star \star} \\
19(15-20)^{\star \star \star} \\
15(4-30)^{\star \star \star} \\
10(10-10) \mathrm{NS} \\
12(8-12)^{\star \star \star} \\
27(14-36)^{\star \star \star} \\
8(4-8)^{\star \star \star}\end{array}$ & $\begin{array}{l}10(3-10)^{\star \star \star} \\
18(11-20)^{\star \star \star} \\
10(0-20)^{\star \star \star} \\
10(9-10) N S \\
11(0-12)^{\star \star \star} \\
23(7-36)^{\star \star \star} \\
7(1-8)^{\star \star \star}\end{array}$ & $\begin{array}{l}10(6-10)^{\star} \\
19(12-20) \mathrm{NS} \\
14(5-26) \mathrm{NS} \\
10(10-10) \text { NS } \\
11 \cdot 5(6-12) \mathrm{NS} \\
25 \cdot 5(11-37) \mathrm{NS} \\
8(4-8) \mathrm{NS}\end{array}$ \\
\hline
\end{tabular}

$\star \mathrm{P}<0.05 ;{ }^{\star \star \star} \mathrm{P}<0.001$. Wilcoxon matched pairs signed rank test. Asterisks in Before column are $v$ Days 2-3; asterisks in days 2-3 are $v$ days 5-9; asterisk in days 5-9 is $v$ Before.

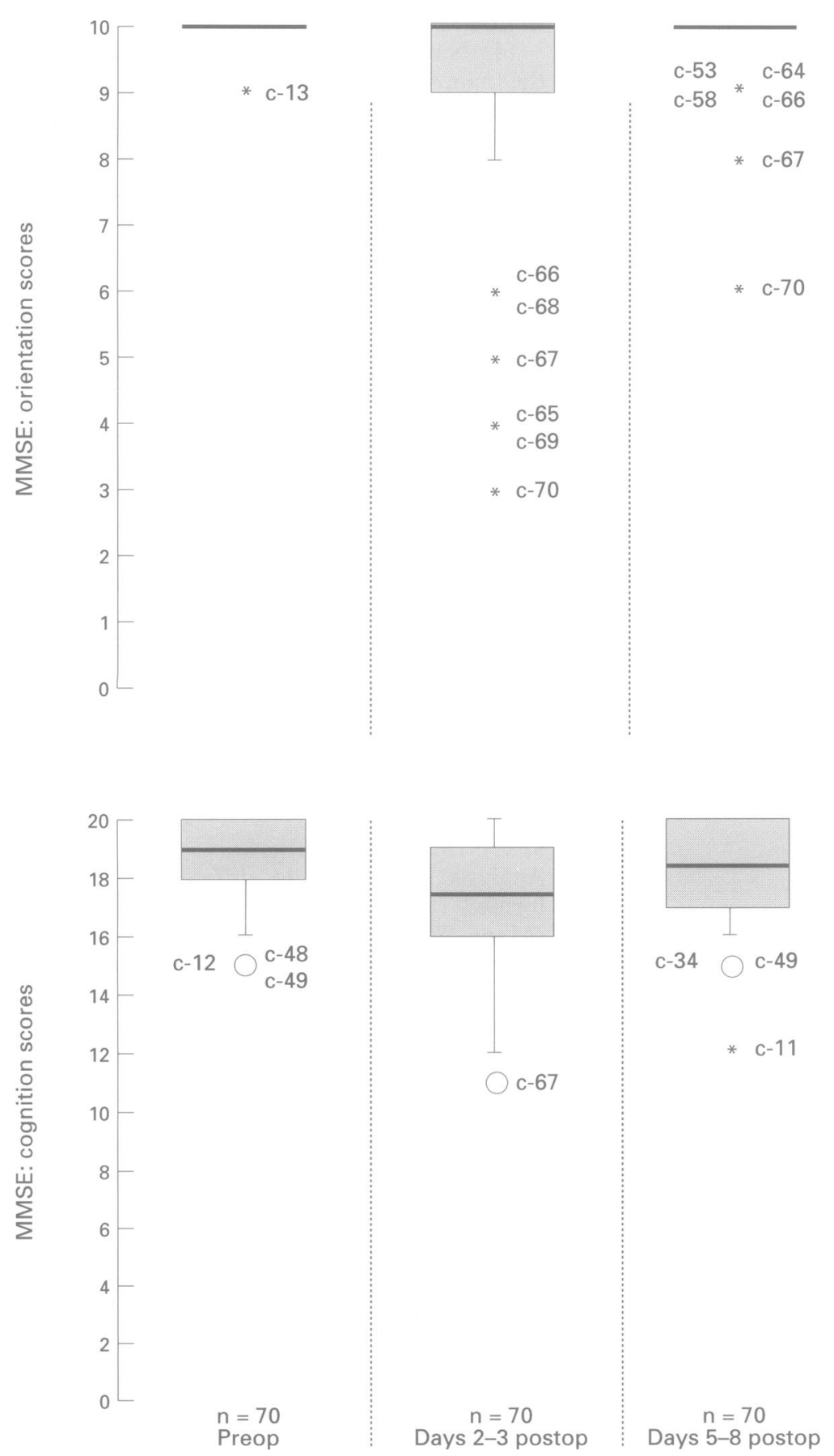

Box plots of the distributions of MMSE scores. $50 \%$ of values falling between 25 th and 75th percentiles; - median; I highest and lowest values excluding outliers; $\bigcirc$ outliers (between 1.5 and 3 box lengths from the upper or lower edge of the box); *extreme values (more than 3 box lengths from upper or lower edge of the box); numbers indicate patients' code. scores. It shows that patients exhibited a downward shift concerning the median and a broader interquartile range in the follow up assessments. Additionally, this figure illustrates that there were many patients with extreme values and outliers in the follow up examinations. Furthermore, not all patients with extreme or outlying values at the second postoperative examination performed outside the 25 th to 75 th interquartile range at the first postoperative examination and vice versa.

Six patients were diagnosed as clinically delirious according to DSM III-R criteria" ${ }^{11}$ at the first postoperative examination and one patient at the second examination.

To identify patients with neuropsychological dysfunctions in the early postoperative stage, we performed a hierarchical cluster analysis based on the neuropsychological performance at the first postoperative assessment. A two cluster solution identified a group of 60 neuropsychologically intact or minimally dysfunctional patients and a second cluster of 10 patients with cognitive impairments. All clinically delirious patients were in cluster II. Table 3 compares both clusters with respect to significant differences in demographic, clinical, and neuropsychological variables.

With the exception of a higher age median of the cluster II patients no significant differences concerning clinical status, medical history, or risk factors between clusters existed preoperatively.

The clusters differed with respect to postoperative course. Patients in cluster II required a greater number of defibrillations after removal from the heart-lung machine, and exhibited lower postoperative cardiac indices and also a lower minimal postoperative stroke volume. A significantly greater proportion required postoperative medication with neuroleptic drugs as a therapeutic response to the presence of delirium. Further significant differences between the two clusters were found at the fifth to ninth day assessment with respect to MMSE orientation and cognition, verbal memory (all $P<0.01)$, word fluency $(P<0.05)$, and confabulations during the verbal memory task ( $\mathrm{P}<0.05)$.

The second aim of our study was to identify risk factors for early postoperative neuropsychological dysfunction that could be assigned to preoperative, perioperative, or postoperative variables. Some postoperative complications may separately contribute to neuropsychological dysfunction; others, such as neuroleptic medication or duration of intensive care treatment, may be a consequence.

To obtain preliminary evidence concerning neuropsychological symptoms that may preoperatively predict postoperative cognitive dysfunction, we retrospectively analysed two groups of 10 cluster I and II patients that were matched for age, sex, number of bypasses, preoperative cardiological status, and preoperative MMSE scores. Although the patients were matched for a widely used screening procedure for cognitive dysfunction and were all in the normal range for MMSE performance, ${ }^{12}$ postoperatively affected patients showed pre- 
Table 3 Differences in demographic, clinical, and neuropsychological variables between unimpaired and impaired clusters of patients

\begin{tabular}{|c|c|c|c|}
\hline & $\begin{array}{l}\text { Cluster I } \\
\text { (unimpaired } \\
n=60 \text { ) } \\
\text { Median (range) }\end{array}$ & $\begin{array}{l}\text { Cluster II } \\
\text { (impaired } \\
n=10 \text { ) } \\
\text { Median (range) }\end{array}$ & $P$ value \\
\hline Age & $60(45-78)$ & $67(53-76)$ & $<0.05$ \\
\hline \multicolumn{4}{|l|}{ Postoperative complications (n (\%)): } \\
\hline Defibrillation post-heart-lung machine & $23(38)$ & $8(80)$ & $<0.01$ \\
\hline Postoperative neuroleptics & $0(0)$ & $3(30)$ & $<0.001$ \\
\hline Postoperative cardiac indices $\left(1 / \mathrm{m}^{2}\right)$ & $2.9(1.9-4.9)$ & $2 \cdot 3(1 \cdot 5-3 \cdot 3)$ & $<0.01$ \\
\hline Min postoperative stroke volume (ml) & $54(21-85)$ & $36(22-55)$ & $<0.05$ \\
\hline \multicolumn{4}{|l|}{$\begin{array}{l}\text { Preoperative neuropsychological } \\
\text { assessment: }\end{array}$} \\
\hline Verbal memory & $27(14-36)$ & $22(16-30)$ & $<0.01$ \\
\hline Confabulations during memory task & $0(0-3)$ & $1(0-5)$ & $<0.05$ \\
\hline \multicolumn{4}{|l|}{$\begin{array}{l}\text { Neuropsychological assessment at } \\
\text { day } 2-3 \text { after bypass: }\end{array}$} \\
\hline MMSE orientation & $10(6-10)$ & $7(3-10)$ & $<0.01$ \\
\hline MMSE cognition & $18(14-20)$ & $14(4-18)$ & $<0.001$ \\
\hline Word fluency & $10(5-20)$ & $5 \cdot 5(0-12)$ & $<0.001$ \\
\hline Arithmetic & $11(5-12)$ & $8 \cdot 5(0-11)$ & $<0.001$ \\
\hline Verbal memory & $24(14-36)$ & $12 \cdot 5(7-14)$ & $<0.001$ \\
\hline \multicolumn{4}{|l|}{ Confabulations during verbal } \\
\hline $\begin{array}{l}\text { memory task } \\
\text { Clock reading }\end{array}$ & $1(0-9)$ & $4(0-7)$ & $<0.001$ \\
\hline \multirow{2}{*}{\multicolumn{4}{|c|}{$\begin{array}{l}\text { Neuropsychological assessment at } \\
\text { day } 5-9 \text { after bypass: }\end{array}$}} \\
\hline & & & \\
\hline MMSE orientation & $10(9-10)$ & $10(6-10)$ & $<0.01$ \\
\hline MMSE cognition & $19(15-20)$ & $17(12-19)$ & $<0.01$ \\
\hline Word fluency & $14(6-26)$ & $12(5-15)$ & $<0.05$ \\
\hline Verbal memory & $27(11-37)$ & $22(15-26)$ & $<0.01$ \\
\hline $\begin{array}{l}\text { Confabulations during verbal } \\
\text { memory task }\end{array}$ & $0(0-7)$ & $1.5(0-4)$ & $<0.05$ \\
\hline
\end{tabular}

operatively significantly lower performance on verbal memory, word fluency tasks $(P<0.01$, Mann-Whitney $U$ test), and clock orientation $(P<0.05$, Mann-Whitney $U$ test $)$.

\section{Discussion}

The present study found a comparatively low rate of $8.6 \%$ for the clinical syndrome of delirium in the postacute stage after neurologically otherwise uncomplicated coronary bypass surgery..$^{913}$ At the first postoperative assessment the patients as a group exhibited signs of cognitive dysfunction, in the MMSE and other neuropsychological tasks with the exception of naming (the task was probably too easy and showed a pronounced ceiling effect). Except for the orientation measurement, patients had largely recovered by the end of the first postoperative week. Our data, however, gave no information concerning the further course of possibly persisting neuropsychological deficits. The instruments used in the present investigation are not suited for the identification of mild cognitive impairment. The literature is equivocal with respect to the long term outcome of cognitive dysfunction after heart surgery. ${ }^{114}$

Cluster analysis of neuropsychological data obtained on the second to third postoperative day disclosed a group of 10 dysfunctional patients, among whom older patients were overrepresented and who had a greater number of postoperative complications. When patients from the clusters of postoperatively largely intact and cognitively compromised patients were matched for demographic data and preoperative MMSE performance, patients with postoperative cognitive dysfunction were characterised by lower preoperative performance in word fluency, verbal memory, and spatial orientation tasks. These preoperatively obtained scores were significant and quite sensitive predictors of the early postoperative cognitive status in retrospective analysis. The data suggest the inclusion of more sensitive but still simple neuropsychological methods beyond the mini mental state examination, such as word fluency, verbal memory, and spatial orientation, in the preoperative prediction of postoperative complications and requirements.

The aetiology of delirium and neuropsychological deficits after coronary surgery remains largely unknown, with only a few causative factors firmly established. Our data indicateand most authors on the subject agree-that postoperative delirium and neuropsychological disorders have a multifactorial aetiology..$^{15-18}$ We therefore consider it valid not to aim primarily at the prediction of postoperative clinical delirium, as it also depends on situational factors. ${ }^{1416}$ Instead, we propose to identify patients who are at risk of developing substantial impairment of cognitive functions postoperatively and thus are prone to be more disturbed and uncooperative. Patients preoperatively identified as being vulnerable to postoperative cognitive dysfunction by simple and short bedside examinations could receive special postoperative care.

Considering the number of coronary bypass operations performed worldwide, the estimate of their risks and benefits in comparison with alternative treatments should include possible long term effects on cognitive functions. However, studies which analyse the persistence of subtle neuropsychological deficits and their influence on long term cognitive status and quality of life are lacking.

We propose further studies of postoperative neuropsychological deficits using a more demanding preoperative neuropsychological assessment including tasks measuring psychomotor speed, attention, verbal and nonverbal memory, and visuoconstructive functions. Based on the findings of the present study, we think that improved preoperative neuropsychological assessment could contribute to the prevention of postoperative confusional states by careful monitoring and treatment of cardiosurgical risk factors and early therapeutic intervention for patients known to be at risk.

We thank Professor V Schlosser, former Director of the Department of Cardiac and Vascular Surgery, Freiburg University, for allowing access to patients under his care, Drs $\mathrm{R}$ Fasol and W Hannes from the same department for providing clinical data, and Dr K Schmidtke, Department of Neurology, Freiburg University, for allowing us to use parts of an unpublished version of a brief clinical assessment of cognitive functions. This study was supported by the State of Baden-Württemberg Research Program in Neuropsychology and Neurolinguistics.

1 Smith LW, Dimsdale JE. Postcardiotomy delirium: conclusion after 25 years? Am $\mathcal{F}$ Psychiatry 1989;146:452-8.

Sotaniemi KA. Cerebral outcome after extracorporeal circulation-comparison between prospective and retroculation-comparison between prospective and

3 Folstein MF, Folstein SE, McHugh PR. "Mini-mentalstate". A practical method for grading the cognitive state state. A practical method for grading the cognitive state of patients.

4 Breuer AC, Furlan AJ, Hanson MR, Lederman RJ, Loop FD, Cosgrove DM. Central nervous system complications of coronary artery bypass graft surgery: prospective analysis of 421 patients. Stroke $1983 ; 14: 682-7$

5 Folks DG, Freeman III AM, Sokol RS, Govier AV, Reves 
JG, Baker DM. Cognitive dysfunction after coronary artery bypass surgery: a case-controlled study. South Med artery bypass surg

6 Götze P, Dahme B. Psychopathological syndroms and neurological disturbances before and after open-heart rological disturbances before and after open-heart
surgery. In: Speidel H, Rodewald G, eds. Psychic and surgery. In: Speidel $\mathrm{H}$, Rodewald $\mathrm{G}$, eds. Psychic and
neurological dysfunction before and after open-heart surgeryneurological dysfunction before and after open-heart surgery-
1st international symposium. New York: Thieme, 1980: 1st internat $48-66$.

7 Tufo HM, Ostfeld AM, Shekelle R. Central nervous system dysfunction following open-heart surgery. $¥ A M A$ 1970;212:1333-40.

8 Dubin WR, Field HL, Gastfriend DR. Postcardiotomy delirium: a critical review. F Thorac Cardiovasc Surg 1979; 77:586-94

9 Kimball CP. Psychological responses to the experience of open heart surgery: I. Am $\mathcal{F}$ Psychiatry 1969;126: 348-59.

10 Treasure T, Smith PLC, Newman S, et al. Impairment of cerebral function following cardiac and other major cerebral function following cardiac and othe

11 American Psychiatric Association. Diagnostic and statistical manual of mental disorders. 3rd ed, revised. Washington,
DC: APA, 1987.

12 Bleecker ML, Bolla-Wilson K, Kawas C, Agnew J. Agespecific norms for the mini-mental state exam. Neurology 1988;38:1565-8.

13 Kimball CP. The experience of open heart surgery-III. Toward a definition and understanding of postcarToward a definition and understanding of postca

14 Shaw PJ, Bates D, Cartlidge NEF, et al. Long-term intellectual dysfunction following coronary artery bypass graft surgery: a six month follow-up study. $Q \mathcal{F}$ Med 1987; 62:259-68.

15 Furlan AJ, Sila CA, Chimowitz ML, Jones SC, Rodman $\mathrm{KD}$. Neurologic complications of cardiac diagnostic procedures, surgery and parmacotherapy. In: Vinken PJ, Bruyn GW, Klawans HL, eds. Handbook of clinical neurology. Amsterdam: Elsevier, 1993:175-204.

16 Lipowski ZJ. Delirium: acute confusional states. Oxford: Oxford University Press, 1990.

17 Smith P, Taylor K. Cardiac surgery and the brain. London: Edward Arnold, 1993.

18 Sotaniemi KA, Mononen H, Hokkanen TE. Long-term cerebral outcome after open-heart surgery-a five year neuropsychological follow-up. Stroke 1986;17:410-6. 